\title{
Teaching Al through Machine Learning Projects
}

\author{
Ingrid Russell \\ University of Hartford \\ West Hartford, CT, USA \\ 01-860-768-4191 \\ irussell@hartford.edu
}

\author{
Zdravko Markov \\ Central CT State University \\ New Britain, CT, USA \\ 01-860-832-2712 \\ markovZ@ccsu.edu
}

\author{
Todd Neller \\ Gettysburg College \\ Gettysburg, PA, USA \\ 01-717-337-6630 \\ tneller@gettysburg.edu
}

\begin{abstract}
An introductory Artificial Intelligence (AI) course provides students with basic knowledge of the theory and practice of AI as a discipline concerned with the methodology and technology for solving problems that are difficult to solve by other means. It is generally recognized that an introductory Artificial Intelligence course is challenging to teach. This is, in part, due to the diverse and seemingly disconnected core AI topics that are typically covered. Recently, work has been done to address the diversity of topics covered in the course and to create a theme-based approach. Russell and Norvig present an agent-centered approach [9]. Others have been working to integrate Robotics into the AI course $[1,2,3]$.
\end{abstract}

We present work on a project funded by the National Science Foundation with a goal of unifying the artificial intelligence course around the theme of machine learning. This involves the development and testing of an adaptable framework for the presentation of core AI topics that emphasizes the relationship between AI and computer science. Machine learning is inherently connected with the AI core topics and provides methodology and technology to enhance real-world applications within many of these topics. Machine learning also provides a bridge between AI technology and modern software engineering. In his article, Mitchell discusses the increasingly important role that machine learning plays in the software world and identifies three important areas: data mining, difficult-to-program applications, and customized software applications [6].

We have developed a suite of adaptable, hands-on laboratory projects that can be closely integrated into the introductory AI course. Each project involves the design and implementation of a learning system which will enhance a particular commonly-deployed application. The goal is to enhance the student learning experience in the introductory artificial intelligence course by (1) introducing machine learning elements into the AI course, (2) implementing a set of unifying machine learning laboratory projects to tie together the core AI topics, and (3) developing, applying, and testing an adaptable framework for the presentation of core AI topics which emphasizes the important relationship between AI and computer science in general, and software development in particular. Details on this project as well as samples of course materials developed are published in $[4,5,7,8]$ and are available at the project website at http://uhaweb.hartford.edu/compsci/ccli.

We present an overview of our work along with a detailed presentation of one of these projects and how it meets our goals.

Copyright is held by the author/owner(s). ITiCSE'06, June 26-28, 2006, Bologna, Italy. ACM 1-59593-055-8/06/0006.
The project involves the development of a learning system for web document classification. Students investigate the process of classifying hypertext documents, called tagging, and apply machine learning techniques and data mining tools for automatic tagging. Our experiences using the projects are also presented.

\section{Categories and Subject Descriptors}

K.3.2 [Computers and Education]: Computer Science Education

General Terms: Experimentation

Keywords: Artificial Intelligence, Projects

\section{ACKNOWLEDGEMENTS}

This work is supported in part by NSF grant DUE CCLI-A\&I Award Number 0409497.

\section{REFERENCES}

[1] Greenwald, L., et al, (ed), Accessible Hands-on Artificial Intelligence and Robotics Education, AAAI Press Technical Report, March 2004

[2] Kumar, A., Using Robots in an Undergraduate Artificial Intelligence Course: An Experience Report, Proceedings of Frontiers in Education Conference, 2001.

[3] Kumar, D., and Meeden, L., A Robot Laboratory for Teaching Artificial Intelligence, Proceedings of SIGCSE, ACM Press, New York, NY, 1998, pp.341-344.

[4] Kumar, A., Kumar, D., Russell, I., "Non-Traditional Projects in the Undergraduate AI Course", Proceedings of the ThirtySeventh SIGCSE Technical Symposium on Computer Science Education, ACM Press, New York, NY, February 2006.

[5] Markov, Z., Russell, I., Neller, T. Proceedings of the ThirtyFifth Annual Frontiers in Education Conference, IEEE Press, October 2005.

[6] Mitchell, T., Does Machine Learning Really Work, $A I$ Magazine, Vol. 18, No. 3, AAAI Press, Fall 1997.

[7] Neller, T., Presser, C., Russell, I., Markov, Z., "Pedagogical Possibilities for the Dice Game Pig", The Journal of Computing Sciences in Colleges, 21(5), May 2006.

[8] Russell, I., Markov, Z., Neller, T., "Unifying an Introduction to Artificial Intelligence Course through Machine Learning Laboratory Experiences", Proceedings of the 2005 Annual American Society for Engineering Education Conference, June 2005.

[9] Russell, S., J. and Norvig, P., Artificial Intelligence: A Modern Approach, Upper Saddle River, NJ: Prentice-Hall, second edition, 2002. 